\title{
Ureia tradicional e protegida no desenvolvimento e produção de forragem de milho
}

O Brasil é destaque junto ao cenário mundial na produção de milho, entretanto o uso de cultivares pouco adaptadas as regiões produtoras, além do baixo uso de fertilizantes nitrogenados em cobertura, reduzem o potencial produtivo das áreas cultivadas com o milho no Brasil. Dessa forma, objetivou-se avaliar o crescimento e produção do milho (Zea mays L.) híbrido RefúgioMax ${ }^{\oplus}$, em função de fontes de adubos nitrogenados (N) (ureia tradicional, ureia protegida). $\mathrm{O}$ experimento foi conduzido em campo, na área experimental do CCAE (Centro de Ciências Agrárias e Engenharias da UFES), localizada no município de Alegre/ES. Foram avaliados 5 tratamentos dispostos em 5 blocos em delineamento experimental de blocos casualizados, onde o tratamento 1 foi a testemunha (Sem dose de $\mathrm{N}$ ). As fontes nitrogenadas testadas foram: ureia tradicional ( $45 \% \mathrm{~N}$ ) nas doses 10 e $20 \mathrm{~g}$ e ureia protegida (Nitro Mais ${ }^{\circledR} 44,6 \% \mathrm{~N}$; B 0,4\% e Cu 0,15\%) 10 e $20 \mathrm{~g}$ por planta em cobertura. A adubação de ureia convencional proporcionou aumento de $19,790 \mathrm{~kg}$ ha-1 e o Nitro Mais ${ }^{\circledR} 25,500 \mathrm{~kg}$ ha- 1 de forragem. Para os índices de clorofila foliar, a adubação de ureia tradicional e protegida proporcionaram um aumento b e total em todas as concentrações, porém a clorofila a foi o único que obteve uma resposta da adubação na dosagem de $10 \mathrm{~g}$ de Nitro Mais. Com base nos resultados, verifica-se que a ureia tradicional e protegida influenciaram na produção de forragem e nos índices de clorofila foliar.

Palavras-chave: Ureia; Zea mays; Produção.

\section{Traditional and protected urea in the development and production of corn forage}

Brazil stands out among the world corn production scene, however the use of cultivars poorly adapted to producing regions, in addition to the low use of nitrogen fertilizers in cover, reduces the productive potential of areas cultivated with corn in Brazil. Thus, the objective was to evaluate the growth and production of corn (Zea mays L.) hybrid RefúgioMax ${ }^{\oplus}$, according to sources of nitrogen fertilizers (N) (traditional urea, protected urea). The experiment was conducted in the field, in the experimental area of the CCAE (Center for Agricultural Sciences and Engineering at UFES), located in the city of Alegre/ES. Five treatments arranged in 5 blocks were evaluated in a randomized block design, where treatment 1 was the control (No dose of $\mathrm{N}$ ). The nitrogen sources tested were: traditional urea ( $45 \% \mathrm{~N}$ ) in doses 10 and $20 \mathrm{~g}$ and protected urea (Nitro Mais ${ }^{\oplus} 44.6 \% \mathrm{~N} ; \mathrm{B} \quad 0.4 \%$ and $\mathrm{Cu} 0.15 \%$ ) 10 and $20 \mathrm{~g}$ per cover plant. The conventional urea fertilization provided an increase of $19,790 \mathrm{~kg}$ ha- 1 and Nitro Mais ${ }^{\circledR} 25,500 \mathrm{~kg}$ ha- 1 of forage. For leaf chlorophyll indexes, the traditional and protected urea fertilization provided aincrease $\mathrm{b}$ and total in all concentrations, however chlorophyll a was the only one that obtained a fertilization response at the dosage of $10 \mathrm{~g}$ of Nitro Mais. Based on the results, it appears that traditional and protected urea influenced the production of forage and the levels of leaf chlorophyll.

Keywords: Urea; Zea mays; Production.

Topic: Proteção de Plantas e Fitotecnia

Reviewed anonymously in the process of blind peer
Received: 05/03/2020

Approved: 21/04/2020
José Raimundo Fraga de Brito (iD)

Universidade Federal do Espírito Santo, Brasil http://lattes.cnpq.br/2627649590171339

http://orcid.org/0000-0002-0174-658X

josefraga_1717@hotmail.com

Leandro Pin Dalvi (iD)

Universidade Federal do Espírito Santo, Brasil

http://lattes.cnpq.br/7662111330884819

http://orcid.org/0000-0002-2995-8007

leandropin@yahoo.com.br

\section{Leonardo Mardgan (iv}

Universidade Federal do Espírito Santo, Brasi

http://lattes.cnpq.br/1061457517778584

http://orcid.org/0000-0002-0966-9566

leonardomardgan2@gmail.com

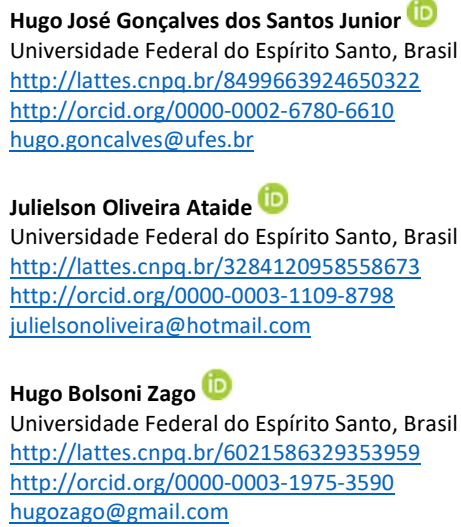

Hugo José Gonçalves dos Santos Junior

Universidade Federal do Espírito Santo, Brasil http://lattes.cnpq.br/8499663924650322

http://orcid.org/0000-0002-6780-6610

hugo.goncalves@ufes.br

Julielson Oliveira Ataide (iD)

Universidade Federal do Espírito Santo, Brasil

http://lattes.cnpq.br/3284120958558673

http://orcid.org/0000-0003-1109-8798

julielsonoliveira@hotmail.com

Hugo Bolsoni Zago (iD)

Universidade Federal do Espírito Santo, Brasil

http://lattes.cnpq.br/6021586329353959

http://orcid.org/0000-0003-1975-3590

hugozago@gmail.com

\section{Referencing this:}

BRITO, J. R. F.; DALVI, L. P.; MARDGAN, L.; SANTOS JUNIOR, H. J. G.; ATAIDE, J. O.; ZAGO, H. B.. Ureia tradicional e protegida no desenvolvimento e produção de forragem de milho. Revista Ibero Americana de Ciências Ambientais, v.11, n.3, p.60-65, 2020. DOI: http://doi.org/10.6008/CBPC2179-6858.2020.003.0006 


\section{INTRODUÇÃO}

Os Estados Unidos lideram a produção mundial, com 370 milhões de toneladas na safra 2017/2018. A China, na segunda posição, foi responsável por 215 milhões de toneladas na safra 2017/2018 e deve chegar a 225 milhões de toneladas em 2018/2019, de acordo com estimativa do USDA (Departamento de Agricultura dos Estados Unidos). O Brasil é atualmente o terceiro maior produtor de milho do mundo com 96 milhões de toneladas produzidas na safra 2017/2018 (CONAB, 2018). Entretanto, esta produção ainda é considerada baixa, pois o nível médio nacional de produtividade é cerca de $3,250 \mathrm{~kg} \mathrm{ha}^{-1}$, uma média baixa comparando com outros sistemas onde são empregados maiores níveis tecnológicos, mostrando que para se alcançar melhores produtividades e rentabilidades para os produtores, diferentes sistemas de produção deverão ser mais aprimorados (CRUZ et al., 2008).

Alguns fatores estão diretamente ligados a essa baixa produtividade do milho no Brasil, entre os quais, podemos citar a baixa densidade de plantio, a implantação da cultura fora da época adequada, o uso de cultivares com baixa adaptação à região e/ou ao sistema de produção adotado, a correção e a adubação do solo empírico (sem análise prévia de solo) e o baixo uso de fertilizantes, especialmente a adubação nitrogenada em cobertura (CRUZ et al., 2009).

Baseando-se nesse contexto, quando se trata em conseguir altas produtividades, a nutrição mineral adequada para cada sistema de cultivo é um dos fatores essenciais para tal sucesso. Por sua vez, o nitrogênio é o elemento que, na maioria das vezes, proporciona os maiores ganhos em produtividade de grãos na cultura (MEIRA, 2006). O Nitrogênio faz parte da constituição das moléculas de proteínas, enzimas, coenzimas, ácidos nucléicos e citocromos (TAIZ et al., 2017). Além disso, desempenha uma importante função integrando a molécula de clorofila, agindo diretamente no sistema de divisão e expansão celular (BULL, 1993).

Sendo assim, conhecer e aprimorar as fontes e doses de nitrogênio a serem aplicadas é de fundamental importância, uma vez que o nitrogênio é muito volátil no solo, devido ao contato direto com uma enzima biológica uréase. Desta forma, o objetivo deste trabalho foi avaliar o crescimento e produção do milho em função das fontes e doses de adubos nitrogenados aplicados em cobertura.

\section{MATERIAIS E MÉTODOS}

O experimento foi conduzido em campo, na área experimental do CCAE (Centro de Ciências Agrárias e Engenharias) na Universidade Federal do Espírito Santo (UFES), localizada em Alegre/ES, Brasil. Sendo os dados da precipitação pluviométrica oriundos da Estação Pluviométrica de Rive, da Agência Nacional de Águas (ANA), situada no município de Alegre, Estado do Espírito Santo, situada nas coordenadas de 20 44' $49^{\prime \prime}$ de latitude $S$, 41 27' 58' de longitude W e altitude de $127 \mathrm{~m}$. De acordo com a classificação internacional de Köppen, o clima da região é do tipo 'Cwa', o que nos refere tropical quente úmido, com inverno frio e seco, temperatura anual média de $23,1{ }^{\circ} \mathrm{C}$ e uma precipitação total anual média de $1341 \mathrm{~mm}$. Antes da instalação do experimento, foi coletada uma amostra de solo da área na profundidade de 0 a $20 \mathrm{~cm}$ e 
realizada a análise química: $\mathrm{pH}\left(\mathrm{H}_{2} \mathrm{O}\right)=6,46, \mathrm{P}=2,52 \mathrm{mg} / \mathrm{dm}^{3}, \mathrm{~K}=2,34 \mathrm{mg} / \mathrm{dm}^{3}, \mathrm{Na}=0 \mathrm{mg} / \mathrm{dm}^{3}, \mathrm{Ca}=2,40$ $\mathrm{mg} / \mathrm{dm}^{3}, \mathrm{Mg}=1,19 \mathrm{mg} / \mathrm{dm}^{3}, \mathrm{Al}=0 \mathrm{cmolc} / \mathrm{dm}^{3}, \mathrm{H}+\mathrm{Al}=0,58 \mathrm{cmolc} / \mathrm{dm}^{3}, \mathrm{SB}=4,18 \mathrm{cmolc} / \mathrm{dm}^{3}, \mathrm{t}=4,18$ $\mathrm{cmolc} / \mathrm{dm}^{3}, \mathrm{~T}=4,76 \mathrm{cmolc} / \mathrm{dm}^{3}, V=87,87 \%, \mathrm{~m}=0 \%$. O solo do local foi classificado como Latossolo Vermelho Amarelo distrófico, de textura média. As irrigações foram realizadas com base nas necessidades evapotranspiratórias, com uma lâmina de água calculada com base nas condições climáticas locais e estádio fenológico da cultura, através de um sistema fixo de irrigação, do tipo aspersão.

A semeadura foi realizada manualmente no dia 14/06/2018, na densidade de 60.000 sementes/ha-1. O plantio foi realizado em covas, no espaçamento de 1,0 m entre linhas, por três covas por metro linear. Em cada cova foi utilizada duas sementes. Foram aplicados $20 \mathrm{~g} /$ cova de Super Simples $\left(18 \% \mathrm{P}_{2} \mathrm{O}_{5}\right)$ e $7,5 \mathrm{~g} /$ cova de Cloreto de potássio $\left(60 \% \mathrm{~K}_{2} \mathrm{O}\right)$. A determinação da dose de cada nutriente baseou-se nos resultados de análise do solo do experimento e na tabela de recomendação de adubação para a cultura do milho, para o estado do Espirito Santo (FERRÃO, 1996). O material de milho (Z. mays) usado foi o híbrido RefúgioMax ${ }^{\circledR}$, de ciclo precoce, não-Bt e resistente ao glifosato.

O delineamento experimental utilizado foi de blocos casualizados, com 5 tratamentos dispostos em 5 blocos. O tratamento 1 foi à testemunha (sem dose de $\mathrm{N}$ ), tratamento 2 (10g ureia convencional), tratamento 3 (20g ureia convencional), tratamento 4 ( $10 \mathrm{~g}$ de Nitro Mais $\left.{ }^{\circ}\right)$ e o tratamento $5(20 \mathrm{~g}$ de Nitro Mais ${ }^{\circ}$ ). As fontes nitrogenadas avaliadas foram: ureia tradicional $\left(45 \% \mathrm{~N}\right.$ ) e ureia protegida (Nitro Mais ${ }^{\circ} 44,6 \%$ $\mathrm{N} ; \mathrm{B} 0,4 \%$ e Cu 0,15\%). As parcelas foram constituídas por 4 linhas de $5 \mathrm{~m}$ de comprimento, sendo que para as avaliações foram consideradas apenas as 2 linhas centrais descartando-se as linhas laterais, totalizando área útil de $6 \mathrm{~m}^{2}$.

O adubo nitrogenado foi aplicado em duas adubações de acordo com o desenvolvimento fenológico do milho. A primeira adubação foi realizada quando mais de $50 \%$ das plantas apresentavam a terceira folha expandida (V3), e a segunda adubação foi quando as plantas apresentavam a sexta folha completamente expandida (V6). $O$ adubo foi posicionado sempre na entrelinha, a uma distância de aproximadamente $20 \mathrm{~cm}$ do colmo das plantas de milho. Após o procedimento de adubação, foi realizada a irrigação.

As avaliações das variáveis, diâmetro do colmo, altura da folha bandeira, índice de clorofila foliar (ICF) e produção de forragem foram realizados no dia 21/08/2018 (embonecamento) e 29/09/2018 (grão farináceo). Os dados obtidos foram submetidos ao teste de comparação de médias e submetidos ao teste de Dunnett a 5\% de probabilidade utilizando o software $\mathrm{SAEG}^{\circ}$ Sistema para Análise Estatística, versão 9.1.

\section{RESULTADOS E DISCUSSÃO}

A utilização de ureia convencional e Nitro Mais em cobertura não influenciou o diâmetro do colmo, assim como a altura das plantas de milho em nenhum dos tratamentos avaliados na tabela 1. Os resultados apresentados podem estar relacionados à volatilização do $\mathrm{N}$ da ureia quando aplicado ao solo, devido ao processo de hidroxilação de $\mathrm{NH}_{4}{ }^{+}$pela ação da enzima uréase (BOLAN et al., 2003). Esta reação origina no aumento temporal do pH na zona de aplicação, o que afeta o equilíbrio entre amônia e amônio (CANTARELLA, 2007). Resultados semelhantes foram obtidos por Maestrelo (2011), que estudando duas fontes de 
nitrogênio (ureia e ureia revestida por polímeros) em quatro doses (0, 40, 80 e $120 \mathrm{~kg} \mathrm{ha}^{-1}$ de N), durante duas safras de verão consecutivas na mesma área, observou que o diâmetro basal do colmo e altura de plantas não foi afetado pelas fontes de nitrogênio na safra 2008/2009. Máximo (2019) e Valderrama et al. (2011), avaliando adubação nitrogenada em cobertura em duas cultivares de milho, também não encontraram diferenças significativas na altura das plantas de milho.

Tabela 1: Diâmetro do colmo, altura da planta, índice de clorofila foliar $\boldsymbol{a}, \boldsymbol{b}$ e total das plantas de milho avaliadas no experimento, em função das doses e fontes de nitrogênio.

\begin{tabular}{|l|l|l|l|l|l|}
\hline Tratamentos & Diâmetro colmo $(\mathbf{c m})$ & Altura da planta $(\mathbf{m})$ & $\begin{array}{l}\text { Clorofila } \\
\boldsymbol{a}\left(\boldsymbol{\mu g} \cdot \mathbf{c m}^{2}\right)\end{array}$ & $\begin{array}{l}\text { Clorofila } \\
\boldsymbol{b}\left(\boldsymbol{\mu g} \cdot \mathbf{c m}^{2}\right)\end{array}$ & $\begin{array}{l}\text { Clorofila } \\
\text { Total }\left(\boldsymbol{\mu g} \cdot \mathbf{c m}^{2}\right)\end{array}$ \\
\hline Testemunha & \multicolumn{1}{|c|}{21,11} & 2,25 & 36,29 & 14,59 & 50,88 \\
\hline 10 g Ureia & $20,73^{\mathrm{NS}} \mathrm{NS}$ & $1,99^{\mathrm{NS}}$ & $37,41^{\mathrm{NS}}$ & $17,7^{*}$ & $55,12^{*}$ \\
\hline 20 g Ureia & $21,35^{\mathrm{NS}} \mathrm{NS}$ & $36,74^{\mathrm{NS}}$ & $17,88^{*}$ & $54,62^{*}$ \\
\hline 10 g Nitro Mais & $23,14^{\circ}$ & $2,06^{\mathrm{NS}}$ & $38,82^{*}$ & $19,07^{*}$ & $57,89^{*}$ \\
\hline 20 g Nitro Mais & $22,04^{\circ}$ & $2,34^{\mathrm{NS}}$ & $37,31^{\mathrm{NS}}$ & $18,75^{*}$ & $56,06^{*}$ \\
\hline
\end{tabular}

$\left({ }^{*}\right)$ significativo superior ou inferior à testemunha, pelo teste de Dunnett, em nível de $5 \%$ de probabilidade; (NS) Não significativo, pelo teste de Dunnett, em nível de 5\% de probabilidade.

Em relação ao índice de clorofila foliar, a fonte Nitro Mais ${ }^{\bullet}$, dose $10 \mathrm{~g}$, foi o único que proporcionou um aumento no teor de clorofila $a$, sendo sua média significativamente maior que a testemunha. Esta diferença apresentada pode estar relacionada à quantidade de nitrogênio presente no solo, pois a clorofila $\boldsymbol{a}$ é formada por um anel de porfirina que contém um grupo metil $\left(-\mathrm{CH}_{3}\right)$ no $\mathrm{C}-3$, diferente da clorofila $b$ que contém um grupo aldeído (-CHO), que substitui o grupo metil- $\mathrm{CH}_{3}$, que tem atração por elétrons (TAIZ et al., 2004). Quanto à clorofila $\boldsymbol{b}$ e total, ambos os tratamentos foram influenciados pelas adubações nitrogenadas, independente das fontes e doses utilizadas. A clorofila $\boldsymbol{b}$ apresentou significância em todos os tratamentos, devido ao efeito atrativo de elétrons de seu grupo aldeído no C-3 (VON ELBE, 2000), por sua vez a clorofila $\boldsymbol{b}$ é um pigmento acessório que auxilia na absorção de luz e na transferência da energia radiante para os centros de reação (TAIZ et al., 2004).

Trabalhando com desempenho agronômico do milho Z. mays em função da adubação nitrogenada, Moreira et al. (2019) não observaram efeito dos tratamentos sobre a clorofila b e clorofila total, porém, a clorofila $a$ foi influenciada pela interação entre as formas de inoculação, quando o $\mathrm{N}$ foi aplicado nos sulcos de semeadura não teve resultado, mas quando inoculado via sementes o $\mathrm{N}$ aumentou o teor de clorofila $\boldsymbol{a}$.

Tabela 2: Massa verde total e Espiga de milho, em função das doses e fontes de nitrogênio.

\begin{tabular}{|l|l|l|}
\hline Tratamentos & $\begin{array}{l}\text { Biomassa fresca } \\
\text { total kg ha-1 }\end{array}$ & \multicolumn{1}{|c|}{ Espiga kg ha-1 } \\
\hline Testemunha & 34,710 & 16,220 \\
\hline 10 g Ureia & $50,800^{*}$ & $22,160^{*}$ \\
\hline 20 g Ureia & $54,500^{*}$ & $23,490^{*}$ \\
\hline 10 g Nitro Mais & $56,052^{*}$ & $23,400^{*}$ \\
\hline 20 g Nitro Mais $^{\bullet}$ & $60,210^{*}$ & $23,720^{*}$ \\
\hline
\end{tabular}

${ }^{*}$ ) significativo superior ou inferior à testemunha, pelo teste de Dunnett, em nível de $5 \%$ de probabilidade; (NS) Não significativo, pelo teste de Dunnett, em nível de 5\% de probabilidade.

Em relação à produção de forragem (biomassa fresca e espigas), todos os tratamentos obtiveram uma produção superior à testemunha conforme descrito na tabela 3. A dose de $20 \mathrm{~g}$ de Nitro Mais obteve $60,210 \mathrm{~kg} \mathrm{ha}^{-1} \mathrm{um}$ ganho de $25,500 \mathrm{~kg} \mathrm{ha}^{-1}$. No entanto $20 \mathrm{~g}$ de ureia convencional produziu $54,500 \mathrm{~kg} \mathrm{ha}^{-1} \mathrm{um}$ 
ganho de 19,790 $\mathrm{kg} \mathrm{ha}^{-1}$. Geralmente, os aproveitamentos de $\mathrm{N}$ decrescem com o aumento das doses aplicadas, tal fato é devido ao suprimento de $\mathrm{N}$ exceder as necessidades da cultura. Por fim, tais decréscimos têm como consequências as perdas de amônia, que aumentam com a dose de aplicação (FERNANDES et al., 2007).

Para o número de espiga, ambas as doses de Nitro Mais apresentaram o mesmo rendimento na produtividade $\left(\mathrm{Kg} \mathrm{h}^{1}\right)$. No entanto na ureia convencional apresentou um acréscimo em $\left(\mathrm{Kg} \mathrm{h}^{1}\right)$ quando houve um aumento na dose. $\mathrm{O}$ efeito positivo do $\mathrm{N}$ sobre a produtividade da cultura de milho é explicado pelo aumento do teor de $\mathrm{N}$ foliar e, principalmente, pela produtividade de espigas $\left(\mathrm{Kg} \mathrm{h}^{1}\right)$ (VALDERRAMA et al., 2011). Todavia essa resposta à adubação depende também de outros fatores, a exemplo dos fatores ambientais e genéticos (FREIRE et al., 2010). Silva et al. (2014) verificaram que $93 \mathrm{Kg} \mathrm{h}^{1}$ de nitrogênio aplicado na cobertura do solo para cultura de milho não influenciaram significativamente no número de espigas por hectare.

\section{CONCLUSÕES}

A ureia tradicional e protegida aumentou a produção de forragem e os índices de clorofila foliar. No entanto o aumento da produção de forragem e do índice de clorofila está relacionado com o aumento da dosagem dos produtos. Entretanto, ureia tradicional e protegida se mostraram eficiente para o desenvolvimento do milho híbrido RefúgioMax ${ }^{\circledR}$.

AGRADECIMENTOS: Ao Conselho Nacional de Desenvolvimento Científico e Tecnológico (CNPq) (Processo no 459790/2014-5), a Fundação de Amparo à Pesquisa e Inovação do Espírito Santo (FAPES) (Processo no: 67675964/2014) e a Coordenação de Aperfeiçoamento de Pessoal de Nível Superior (CAPES), pelas bolsas e auxílios concedidos.

\section{REFERÊNCIAS}

BOLAN, N. S.; HEDLEY, M. J.. Role of carbon, nitrogen, and sulfur cycles in soil acidification. In: RENDEL, Z.. Handbook of soil acidity. New York: Marcel Dekker, 2003. p.29-56.

BULL, L. T.. Nutrição mineral do milho. In: BULL, L.T.; CANTARELLA, H.. Cultura do milho: fatores que afetam a produtividade. ed. Potafos. Piracicaba, p.63-145,1993.

CANTARELLA, H.. Nitrogênio. In: NOVAIS, R. F.. Fertilidade do Solo. Viçosa: Sociedade Brasileira de Ciência do Solo, 2007.

CONAB. Companhia Nacional de Abastecimento. Boletim da safra de grãos. CONAB, 2018.

CRUZ, J. C.; PEREIRA FILHO, I. A.; GRARCIA, J. C.; GOMES, P. H. A.; FERNANDES, J. S. C.; ALBERNAZ, W. M.. Avaliação de sistemas de produção de milho na região de Sete Lagoas, MG. Sete Lagoas: Embrapa Milho e Sorgo, 2009.

CRUZ, S. C. S.; PEREIRA, F. R. S.; SANTOS, J. R.; ALBUQUERQUE, A. W.; PEREIRA, R. G.. Adubação nitrogenada para o milho cultivado em sistema plantio direto, no Estado de Alagoas. Revista Brasileira de Engenharia Agrícola e Ambiental, v.68, p.12-62, 2008.

FERNANDES, A. R. M.; SAMPAIO, A. A. M.; HENRIQUE, W.; PERECIN, D.; OLIVEIRA, E. A.; TÚLLIO, R. R.. Avaliação econômica e desempenho de machos e fêmeas Canchim em confinamento alimentados com dietas à base de silagem de milho e concentrado ou cana-de-açúcar e concentrado contendo grãos de girassol. Revista Brasileira de Zootecnia, Viçosa, v.36, n.4, p.855-864, 2007.

FERRÃO, R. G.; GALVÊAS, P. A. O.; SANTOS, J. A. C.; FERRÃO, M. A. G.; GAMA, E. E. G; DESSAUNE FILHO, N.. Cultivares de Milho para o Estado do Espírito Santo. Revista Ceres, v. 43, n. 246, p. 186-199, 1996.

FREIRE, F. M.; VIANA, M. C. M.; MASCARENHAS, M. H. T.; PEDROSA, M. W.; COELHO, A. M.; ANDRADE, C. L. T. Produtividade econômica e componentes da produção de espigas verdes de milho em função da adubação 
nitrogenada. Revista Brasileira de Milho e Sorgo, v.9, p.213222, 2010.

MAESTRELO, P. R.. Ureia e ureia revestida por polímeros em milho e feijoeiro de inverno sob sistema de semeadura direta. Monografia (Bacharelado em Agronomia) Universidade Estadual Paulista, Ilha Solteira, 2011.

MÁXIMO, P. J. M.; PINTO, A. A.; CAMARA, F. T.; MOTA, A. M. D.; NICOLAU, F. E. A.. Adubação nitrogenada em cobertura em dois cultivares de milho no Cariri/CE. Revista de Agricultura Neotropical, Cassilândia, v.6, n.1, p.23-28, 2019.

MEIRA, F. A.. Fontes e modos de aplicação do nitrogênio na cultura do milho. Tese (Doutorado em Agronomia, Engenharia) - Universidade Estadual Paulista, Ilha Solteira, 2006.

MOREIRA, R. C.; VALADÃO, F. C. A.; VALADÃO JÚNIOR, D. D.. Desempenho agronômico do milho em função da inoculação com Azospirillum brasilense e adubação nitrogenada.

Revista Ciências Agraria, v. 62, p. 1-10, 2019.
SILVA, G. F.; OLIVEIRA, F. H. T.; PEREIRA, R. G.; SILVA, P. S. L.; DIÓGENES, T. B. A.; SILVA, A. R. C.. Doses de nitrogênio e fósforo para produção econômica de milho na Chapada do Apodi, RN. Revista Brasileira de Engenharia Agrícola e Ambiental, v.18, n.12, p.1247-1254, 2014. DOI: https://doi.org/10.1590/1807-1929/agriambi.v18n12p1247$\underline{1254}$

TAIZ, L.; ZEIGER, E.. Fisiologia e Desenvolvimento Vegetal. 6 ed. São Paulo, 2017.

TAIZ, L.; ZIEGLER, E.. Fisiologia vegetal. 3 ed. Porto Alegre: Artmed, 2004.

VALDERRAMA, M.; BUZETTI, S.; BENETT, C. G. S.; ANDREOTTI, M.; TEIXEIRA FILHO, M. C. M.. Fontes e doses de NPK em milho irrigado sob plantio direto. Pesquisa Agropecuária Tropical, v.41, p.254-263, 2011.

VON ELBE J. H.. Colorantes. In: FENNEMA, O. W.. Química de los alimentos. 2 ed. Zaragoza: Wisconsin - Madison, 2000.

A CBPC - Companhia Brasileira de Produção Científica (CNPJ: 11.221.422/0001-03) detém os direitos materiais desta publicação. Os direitos referem-se à publicação do trabalho em qualquer parte do mundo, incluindo os direitos às renovaç̃oses, expansões e disseminações da contribuiç̃o, bem como outros direitos subsidiários. Todos os trabalhos publicados eletronicamente poderão posteriormente ser publicados em coletâneas impressas sob coordenação da Sustenere Publishing, da Companhia Brasileira de Produção Científica e seus parceiros autorizados. Os (as) autores (as) preservam os direitos autorais, mas não têm permissão para a publicação da contribuição em outro meio, impresso ou digital, em português ou em tradução. 